from the outermost fringes of the universe. It will be slightly smaller than that of the only other giant radio telescope at present in existence (at Jodrell Bank, England). However, the surface accuracy of the Australian radio telescope and the precision with which it can be pointed and driven will all be substantially higher.

\section{Proton Linear Accelerator}

THE 50 million electron volt proton linear accelerator at the Rutherford High Energy Laboratory, Harwell, came into operation on July 12. This is the first accelerator at the National Institute for Research in Nuclear Science to come into operation. It will be used for nuclear research by physicists from universities, the Atomic Energy Authority and a resident team based at the Rutherford Laboratory. When in full operation it is expected to have a proton beam intensity many times greater than other accelerators of this kind. Because of the high intensity and very well-defined energy it will be possible to do experiments of great value in the study of the interaction between nuclear particles. The main parts of the accelerator were designed and constructed for the Atomic Energy Authority by Metropolitan Vickers, Ltd., in collaboration with a team of physicists and engineers from the Atomic Energy Research Establishment who also carried out basic development work on the accelerating structures, and were responsible for the other parts of the machine.

\section{High-Pressure Oxygen and Radiotherapy}

IT is now well established that when certain cells are deprived of oxygen they become more radioresistant, and recent work has demonstrated a similar effect upon malignant cells. Thomlinson furthermore suggested that in some malignant tumours a proportion of the cells were deficient in oxygen, due essentially to an inadequate local circulation, which could lower their radiosensitivity. On this basis, Dr. I. ChurchillDavidson, Dr. C. Sanger and Dr. R. H. Thomlinson started in 1954 at the Radiotherapy Department of St. Thomas's Hospital a preliminary investigation of the effects of irradiating certain malignant tumours in patients breathing 15-20 times the normal amount of oxygen while in a pressure chamber, which had been designed and presented by Sir Robert H. Davis. To obtain adequate irradiation at a depth without severe skin damage, $\gamma$-rays from a cobalt teletherapy unit were used.

Preliminary results in the treatment of advanced carcinomas were encouraging, and in order to try to overcome the limitations of the early prototype apparatus a new unit, specially designed for this purpose, has recently been installed at St. Thomas's Hospital. Essentially, the unit consists of an alum. inium pressure chamber, also presented by Sir Robert Davis, into which are led oxygen pipes and multiple leads which enable the patient to be kept under controlled anæsthesia and observed electronically, although not seen, during treatment. A twinheaded cobalt-60 teletherapy unit has also been installed with this chamber, so designed in order to reduce the time of treatment to a minimum.

\section{River Purification}

THE growth of population and industry has produced problems of river management which had not been foreseen and are not capable of immediate solution. Many of the worst cases in Britain are in areas where industry developerd and population grew rapidly between 1750 and 1850 ; the seriousness of the problem was not appreciated until it had reduced many of the rivers to an appalling condition. It was, however, a very long time before it was appreciated that the effects of modern developments in industry and in urbanization on surface waters must be taken into account when plans for the future are being made. Even as late as the 1920's the establishment of the beet sugar industry in Britain gave rise to an alarming pollution problem which threatened to turn many of the rivers in our rural areas into a condition as foul and offensive as those in the old industrial areas. About the same time, the growth of road transport led to the use of tar as a surfacing material for roads and that gave rise quite unexpectedly to a pollution problem which could have had serious effects on fisheries had it not been tackled in time. From then on it began to be realized that the prevention of pollution was, in fact, a practicable proposition and was possible if those concerned, whether industry, local authority or river authority, appreciated the problems and discussed them with other water interests before the waste waters had to be discharged. Eventually, this arrangement became an integral part of the Rivers (Prevention of Pollution) Act, 1951, which provides that the consent of a river board is necessary to any new discharge made into non-tidal waters. According to F. T. K. Pentelow, of the Fisheries Department, Ministry of Agriculture, Fisheries and Food (Science Progress, 47, No. 185 ; January 1959), that change of policy seems to be having good results, for the very considerable industrial expansion which has occurred since the War has not, so far, given rise to pollution problems on anything like the scale it would have done one hundred years ago.

\section{Federation of British Industries}

In the forty-second annual report of the Federation of British Industries for 1958 (pp. vi +42 . London : Federation of British Industries, 1959) it is stated that the gradual discontinuance of research on defence projects sponsored by Government departments has necessitated a fundamental appraisal of the future finance and organization of industrial research. Discussions at the National Production Advisory Council on Industry showed that the Government's plans put forward by the office of the Lord President of the Council required a detailed statement of industry's point of view. The Federation's Industrial Research Committee has already formulated an interim statement, which was submitted to the Advisory Council in June 1958, and is now undertaking a detailed study of certain aspects of British research practice in relation to methods adopted abroad. The report also notes the establishment by the Federation's Education Committee, in co-opera. tion with representatives of the Publishers' Associa. tion, Aslib, the universities and the technical colleges, of a panel to investigate the alleged shortage of advanced British text-books.

\section{Technological Education in Britain}

THe tenth annual report of the London and Home Counties Regional Advisory Council for Technological Education (pp. 28. London, 1958) covers the year ended August 31, 1958, and refers to a complete re. organization of the Council. Under its new constitution, the approval of location of courses under the Ministry of Education's Administrative Memorandum 545 will be carried out by the Distribution of 